\title{
Water Boosts the Performances of Glass Anodes for Lithium-Ion Batteries
}

\author{
Zhenjing Jiang ${ }^{\mathrm{a}, 1}$, Shibin $\mathrm{Qi}^{\mathrm{a}, 1}$, Chengwei Gao ${ }^{\mathrm{b}}$, Xiangyu $\mathrm{Li}^{\mathrm{a}}$, Yanfei Zhang ${ }^{\mathrm{a},{ }^{*}}$, Yuanzheng Yue ${ }^{\mathrm{b}, *}$ \\ ${ }^{\text {a }}$ School of Materials Science and Engineering, Qilu University of Technology (Shandong Academy of \\ Sciences), Jinan 250353, China \\ ${ }^{b}$ Department of Chemistry and Bioscience, Aalborg University, 9220 Aalborg, Denmark \\ ${ }^{1}$ These authors contributed equally to this work. \\ * Corresponding Authors. E-mail: zhang-yanfei@hotmail.com (Y.Z.); yy@bio.aau.dk (Y.Y.)
}

\begin{abstract}
Owing to their disordered open network structure, oxide glasses are a promising class of anode materials for Lithium-Ion Batteries (LIBs). However, the relatively low capacities of glass anodes severely limit their practical application for large energy storage devices. Here we show an unconventional novel approach, which significantly enhances the electrochemical performances of glass anodes for LIBs. Specifically, we incorporated water into an electrochemically active glass system, i.e., $\mathrm{TeO}_{2}-\mathrm{V}_{2} \mathrm{O}_{5}-\mathrm{P}_{2} \mathrm{O}_{5}$ (TVP) glass powder via humidity treatment, and then mix the hydrated powder with additives to fabricate anode. The optimized humidity treatment led to the structural modification of the TVP glass powder, which boosted the capacity of the TVP anode by more than $200 \%$, and maintained the reversible capacity for extra-long cycles. The boosted performances are associated both with the depolymerized structural network for $\mathrm{Li}^{+}$diffusion and with the hydrationinduced nanocrystals. These findings help develop superior glass electrodes in an economically effective way.
\end{abstract}

Keywords: Li-ion battery; Glass anode; Humidity treatment; Water chemistry; Electrochemical performances 


\section{Introduction}

Recently, oxide glasses with polyvalent ions as rising-star electrode materials for lithium-ion batteries (LIBs) have aroused considerable research interest [1-7]. Particularly, the successful attempt of Idota's group [8] to apply $\mathrm{SnO}_{2}$-based glass as anode material for LIBs signified both the fascination and importance of the oxide glass anodes and resulted in advances in energy storage technology. In terms of microstructure, oxide glass possesses various advantages for serving as electrode material[1-3] and these unique features render it a bright future for diverse applications in energy storage devices. Driven by these aspects, numerous studies have been done to investigate oxide glass anodes from different aspects, such as compositions [1,3,7], fabrication methods [9,10], as well as microstructures [11-13]. Recently, our group found that the lithiation/delithiation induced the formation of nanocrystals in the glass matrix of anode material. These nanocrystals greatly contribute to the reduction of $\mathrm{Li}$-ion diffusion path length, improvement of the ionic conductivity and maintaining the structural stability of the anode materials over multiple charge-discharge cycles $[1,14,15]$. However, the reversible capacity of oxide glass anode, especially its volumetric lithium storage, is still far from the requirement for miniaturization of energy storage devices [16,17]. In particular, the limited capacity of glass anode is related to their poor ionic conductivity at the ultrahigh current density, which results in slow transfer kinetics of $\mathrm{Li}^{+}$ions. These problems severely limit the practical applications of LIBs with competent rate capability and ultrahigh cycling stability.

Phosphate glasses is an important branch of functional material and have been widely used in many different fields, including biomedicine [18-20], sealing materials [21,22], optical materials [23], solidification of nuclear waste [24], solid electrolyte and electrode material [25,26], by virtue of their 
excellent chemical and physical properties. Most of phosphate glasses feature linear chain-like structure of covalently linked P-tetrahedra through bridging oxygens [27]. The cross-link structure is realized by the connection of various modifier ions rather than P-O-P backbone, resulting in a weak chemical stability. This is the main reason why the phosphate glasses are easily corroded by aqueous solution [28-30]. That is, they are easily eroded by the hydration process, and hence, their applications are hindered in various areas $[31,32]$.

On the other hand, we are also curious about whether water could pose some positive impact on the electrochemical properties of phosphate glasses as anode materials in LIBs. After a careful literature survey, we found some reports on the role of water incorporation in enhancing both the electrochemical properties and the ionic conductivity of oxide materials [33-37]. Specifically, the structural water can increase proton conductivity in phosphate glasses since the weaker O-H bonding contributes to the higher mobility of proton carriers [35-38]. Moreover, the structural water can enhance the kinetics of energy storage in transition metal oxides by converting the battery-like behavior into ideally pseudocapacitive behavior [34]. These results have broad implications for understanding the relationship between the structure and property for a variety of hydrous oxide systems.

All the above-mentioned aspects motivated us to conduct a systematic study with respect to the impact of water on the electrochemical performances of the $\mathrm{TeO}_{2}-\mathrm{V}_{2} \mathrm{O}_{5}-\mathrm{P}_{2} \mathrm{O}_{5}$ (TVP) glass-based anode for LIBs. We subjected the TVP glass powders to different degree of humidity treatment at constant temperature. The water-reacted glass powders were mixed with additives to fabricate the anodes for LIBs. We characterized the electrochemical properties of the water-reacted TVP glass 
anodes and evaluated their dependence on humidity. An optimum humidity was found, which caused an enhancement of the $\mathrm{Li}$ ion storage capacity by $133 \%$, i.e., from $180 \mathrm{~mA} \mathrm{~h} \mathrm{~g}^{-1}$ for the 'dry' glass anode to $420 \mathrm{~mA} \mathrm{~h} \mathrm{~g}^{-1}$ for the anode based on the $65 \%$ humidity treated glass. The origin of this significant enhancement is thoroughly investigated in this work.

\section{Experimental Section}

\subsection{Sample preparation}

The starting material used in this study was the vanadium-tellurite-phosphate glass, which was applied as the anode material for LIBs in a previous report [26]. The glass with the nominal molar composition of $20 \mathrm{TeO}_{2}-60 \mathrm{~V}_{2} \mathrm{O}_{5}-20 \mathrm{P}_{2} \mathrm{O}_{5}$ (TVP) was prepared via the melt quenching method from the reagent grade $\mathrm{TeO}_{2}, \mathrm{~V}_{2} \mathrm{O}_{5}$ and $\mathrm{NH}_{4} \mathrm{H}_{2} \mathrm{PO}_{4}$ powders following the procedure described elsewhere [26]. The humidity experiment was carried out by keeping the 'dry' TVP glass powders (i.e., the asreceived glass powders that was not hydrated.) in an environmental chamber (HWS-508). To investigate exclusively the effect of relative humidity $(\mathrm{RH})$ on the performance of TVP glasses, the glass powders were treated under three different RH conditions, i.e., 45, 65 and 85 RH\%, for $120 \mathrm{~h}$ at $333 \mathrm{~K}$, respectively (Fig. S3). After the treatment, the samples were taken out from the chamber immediately. The corresponding samples were named as $45 \mathrm{RH}, 65 \mathrm{RH}$ and $85 \mathrm{RH}$, respectively.

\subsection{Cell assembly and Electrochemical measurements}

The electrochemical tests of the 'dry' TVP, $45 \mathrm{RH}, 65 \mathrm{RH}$ and $85 \mathrm{RH}$ glass anodes were performed using two-electrode coin cell with Li foils serving as both the counter electrode and the reference one [17]. The procedure of the cell assembly was described elsewhere [1, 18, 26]. Cyclic voltammetry 
(CV) measurements were performed on an electrochemical workstation (PARSTAT 3000A DX) at a scan rate of $0.1 \mathrm{mV} \mathrm{s}^{-1}$ in the voltage range of $0.01-3.0 \mathrm{~V}\left(\mathrm{vs} \mathrm{Li} / \mathrm{Li}^{+}\right)$. Electrochemical impedance spectroscopy (EIS) measurements were carried out using the impedance-measuring unit (PARSTAT 3000A DX electrochemical workstation) with AC signal amplitude of $5 \mathrm{mV}$ in the frequency range of $100 \mathrm{kHz}$ to $0.02 \mathrm{~Hz}$.

\subsection{Material Characterization}

The phase analysis of all the samples were performed on an X-ray diffractometer (XRD, Shimadzu LabX XRD-6100, $\mathrm{CuK} \alpha$ radiation). The isobaric heat capacity $\left(C_{\mathrm{p}}\right)$ of all the samples was measured using differential scanning calorimetry (DSC) (Netszch Jupiter STA 449F3, Selb, Germany) at the heating rate of $10 \mathrm{~K} / \mathrm{min}$ in the purged $\mathrm{N}_{2}$ atmosphere. X-ray photoelectron spectroscopy (XPS) measurements were carried out with an ESCALAB 250Xi spectrometer. Fourier transform infrared (FTIR) spectra were collected by a Thermo Fisher IS10 spectrophotometer (America) with KBr pellet method.

\section{Results and Discussion}

\subsection{Analyzing the incorporated water in TVP glass and phase identification}

Fig. 1a shows the XRD patterns of the 'dry' TVP glass and the ones treated under different RH conditions, e.g., 45RH, 65RH and $85 \mathrm{RH}$ samples, respectively. The broad hump verifies the amorphous nature of the starting TVP glass sample. However, the Bragg peak starts to appear and becomes more pronounced when the 'dry' TVP glass was exposed to the increasing RH from $45 \%$ to $85 \%$, indicating that the humidity treatment could induce crystallization in TVP glass with "water" 
(e.g., hydroxyl groups) in the structure. Such "water" could reside in the form of -H, -OH as well as loosely bounded water molecules. The phase identification indicates the formation of $\mathrm{H}_{4} \mathrm{~V}_{3} \mathrm{P}_{3} \mathrm{O}_{16.5}$. $\mathrm{xH}_{2} \mathrm{O}$ (JCPDS 47-0967) crystals in the three hydrated samples. It should be noted that not all peaks could be identified, especially, those in $85 \mathrm{RH}$ sample.
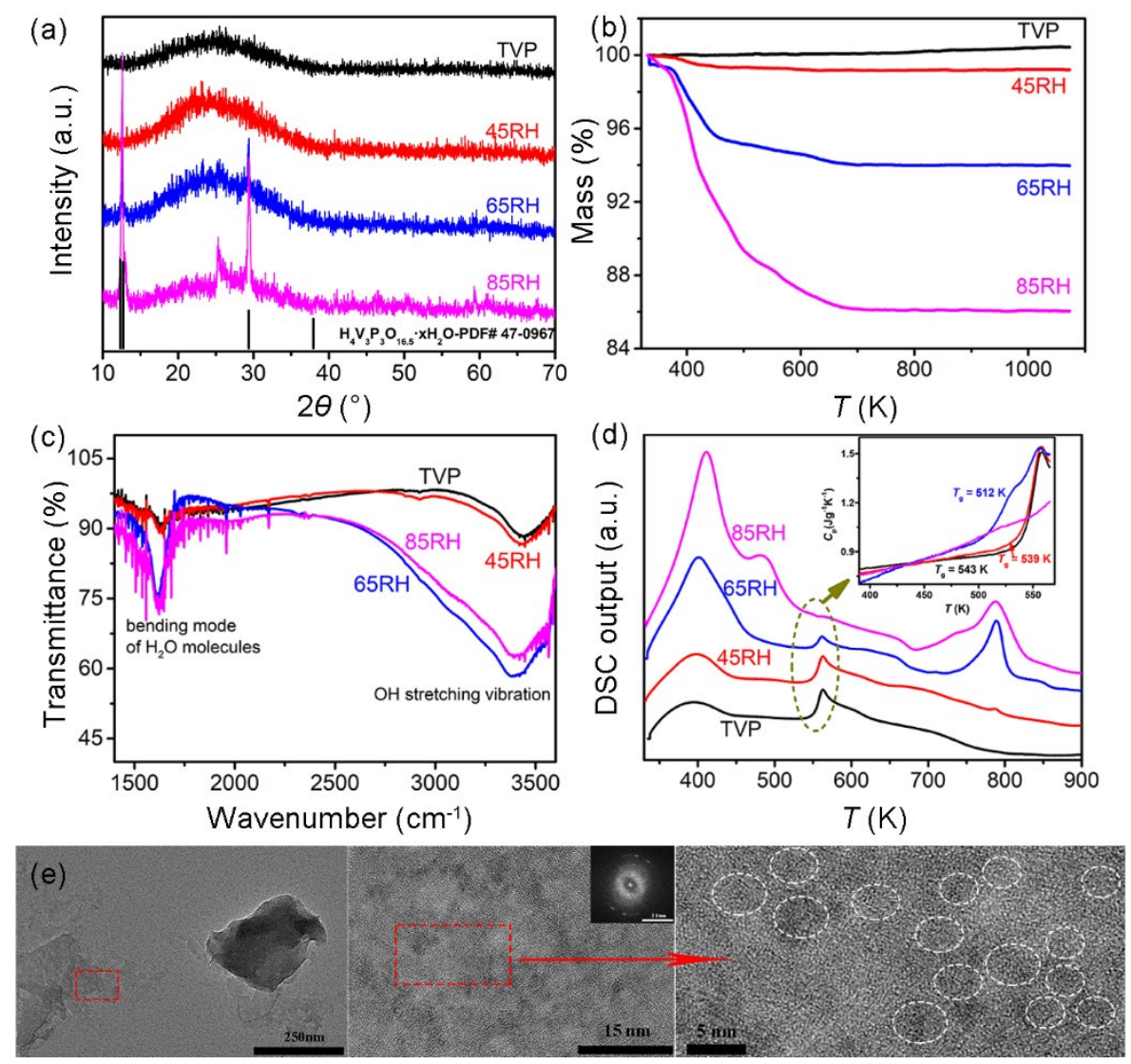

Fig. 1. (a) XRD patterns, (b) TGA curves, (c) FTIR spectra and (d) DSC curves of the 'dry' TVP glass and the ones treated at different RH, e.g., 45RH, $65 \mathrm{RH}$ and $85 \mathrm{RH}$, respectively for $120 \mathrm{~h}$ at $333 \mathrm{~K}$. (e) the HRTEM images of 65RH sample illustrating the randomly distributed nano-crystals induced by hydration in the glass matrix.

To confirm the presence of a significant fraction of water in the structure of the three treated samples and to investigate the kinetics of dehydration, thermogravimetric analysis (TGA) of the TVP, 
45RH, $65 \mathrm{RH}$ and $85 \mathrm{RH}$ samples were conducted by heating to $1073 \mathrm{~K}$ at $10 \mathrm{~K} \mathrm{~min}^{-1}$. As shown in Fig. 1b, the mass percentage of the 'dry' TVP glass remains nearly constant during heating. However, the TGA curves of $45 \mathrm{RH}, 65 \mathrm{RH}$ and $85 \mathrm{RH}$ samples exhibited mass loss upon heating. The mass loss becomes more pronounced with increasing RH, implying that a larger amount of water resides in TVP glass when treated at higher RH condition [20,39] ((Fig. S1)). In the three hydrated samples, the mass loss occurs at the onset temperature of about $400 \mathrm{~K}$, which corresponds to the removal of physically absorbed water, and then approaches the plateaus of 94 and $86 \%$ for $65 \mathrm{RH}$ and $85 \mathrm{RH}$, respectively, up to about $700 \mathrm{~K}$, indicating the release of structurally bonded - $\mathrm{OH}$ groups and/or crystal water. The mass loss trend suggests the presence of the versatile bonded $\mathrm{H}_{2} \mathrm{O}$ and $-\mathrm{OH}$ species in the samples, which can be utilized to fine-tune the microstructure and further to improve the electrochemical properties of the studied samples.

Since the $-\mathrm{OH}$ species in the oxide materials have great influence on the electrochemical performances $[32,33]$, it is necessary to further explore the existence of $-\mathrm{OH}$ species in the three hydrated samples. FT-IR spectra shown in Fig. 1c display the clear evolution of the multiple board peaks in the TVP glass samples upon the humidity treatment. The peak located at $\sim 3450 \mathrm{~cm}^{-1}$ originated from the stretching vibration modes of the fundamental $-\mathrm{OH}$ in both $\mathrm{OH}^{-}$and $\mathrm{H}_{2} \mathrm{O}$ molecules [40] while that located at $\sim 1630 \mathrm{~cm}^{-1}$ is ascribed to the molecular $\mathrm{H}_{2} \mathrm{O}$ bending mode $[41,42]$. The intensity of both peaks gradually increases with increasing the relative humidity, suggesting that more active -OH groups were generated in the samples.

Fig. 1d shows the DSC curves of the studied four samples. The endothermic peak at around $400 \mathrm{~K}$ become more intense from $65 \mathrm{RH}$ to $85 \mathrm{RH}$ samples. Combining with the TGA results in Fig. $1 \mathrm{~b}$, this 
endothermic peak could be associated with the release of water absorbed during hydration. In addition, DSC curves of TVP, 45RH and 65RH demonstrate pronounced glass transition peaks while no glass transition peak could be observed in the DSC upscan of $85 \mathrm{RH}$. The glass transition temperature $\left(T_{\mathrm{g}}\right)$ decreases from $543 \mathrm{~K}$ (for 'dry' TVP) to $512 \mathrm{~K}$ (for $65 \mathrm{RH}$ ) with the increasing humidity as clearly displayed in the inset of Fig. 1d. It is important to mention that no glass transition peak appears in 85RH sample, instead, an endothermic peak occurs at about $485 \mathrm{~K}$. This peak might arise from the loss of covalently bounded $\mathrm{H}_{2} \mathrm{O}$ in the $\mathrm{H}_{4} \mathrm{~V}_{3} \mathrm{P}_{3} \mathrm{O}_{16.5} \times \mathrm{xH}_{2} \mathrm{O}$ crystals, which originate from the crystallization of almost all the glass matrix as confirmed by the XRD pattern (Fig. 1a). This is also why no glass transition peak appears in the DSC curve of $85 \mathrm{RH}$ sample. With the further increased scanning temperature, no obvious thermal events occur in TVP glass sample, but a very tiny endothermic peak appears at $787 \mathrm{~K}$ for $45 \mathrm{RH}$ sample, which might be due to the melting of $\mathrm{H}_{4} \mathrm{~V}_{3} \mathrm{P}_{3} \mathrm{O}_{16.5} \cdot \mathrm{xH}_{2} \mathrm{O}$ crystals generated during the hydration treatment, as confirmed in Fig. 1a. As a universal rule, the broad exothermic peak at around $700 \mathrm{~K}$ in each DSC curve of $65 \mathrm{RH}$ and $85 \mathrm{RH}$ samples, respectively, is caused by crystallization, while the subsequent endothermic peak is due to the melting of crystals. However, the real origin of the two peaks is contrary to the conventional wisdom, which is discussed in the following section.

In order to directly observe and understand the microstructure of the hydrous samples, the HRTEM images of $65 \mathrm{RH}$ sample as a representative are displayed in Fig. 1e. Obviously, many ordered domains with regular lattice fringes denoted by the ellipse are spatially dispersed in the glass matrix. The mean size of the ordered domains is about $5 \mathrm{~nm}$. This implies that the formed crystals in TVP glass, which are induced by hydration under different RH conditions, have a nano-size. These 
nanocrystals lead to the Bragg peaks in the XRD patterns (Fig. 1a).
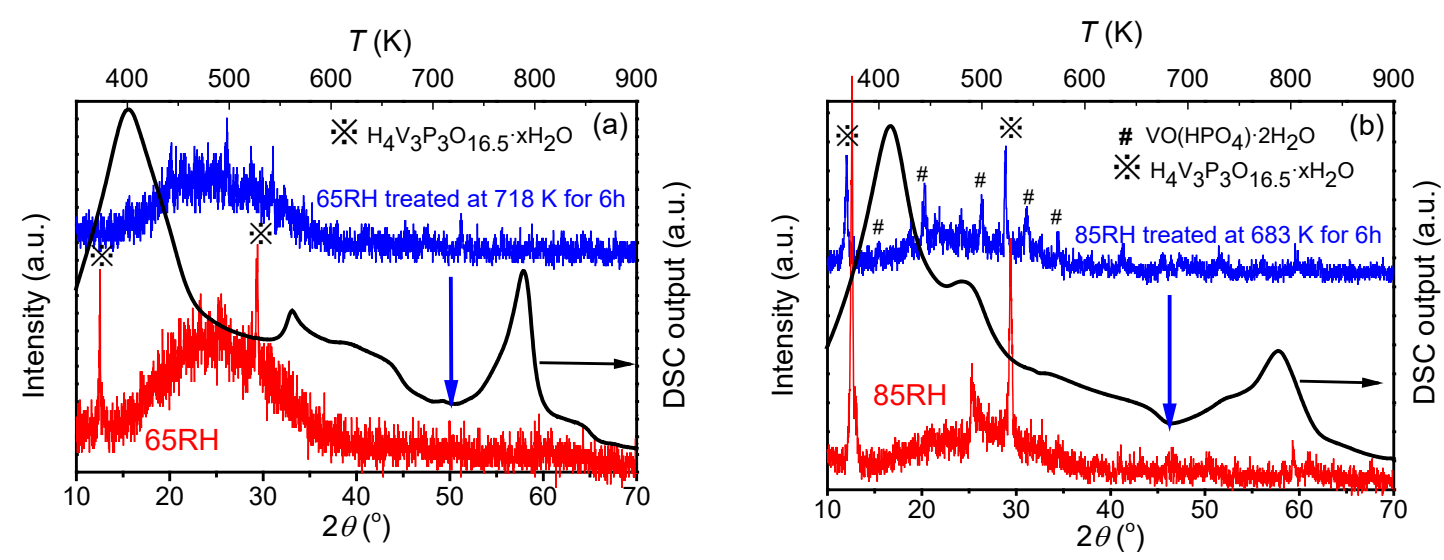

Fig. 2. The first DSC upscan curves (the black line) of both (a) $65 \mathrm{RH}$ and (b) $85 \mathrm{RH}$ samples, along with the XRD patterns of the two samples (the red line) and the ones heat-treated at the temperature denoted by the arrows in the respective DSC curves (the blue line), i.e., 718 and $683 \mathrm{~K}$, respectively.

To explore the origin of the exothermic peaks at $718 \mathrm{~K}$ and $683 \mathrm{~K}$ in DSC upscans (the black lines in Fig. 2) of both $65 \mathrm{RH}$ and $85 \mathrm{RH}$ samples, respectively, as well as to verify the stability of the crystals, i.e., $\mathrm{H}_{4} \mathrm{~V}_{3} \mathrm{P}_{3} \mathrm{O}_{16} \cdot 5 \cdot \mathrm{xH}_{2} \mathrm{O}$, formed during the hydration process, these two samples were heattreated at 718 and $683 \mathrm{~K}$ for 6 hours, respectively. The XRD patterns of $65 \mathrm{RH}, 85 \mathrm{RH}$ and the heattreated samples are shown in Fig. 2. Strikingly, the Bragg peaks which are assigned to $\mathrm{H}_{4} \mathrm{~V}_{3} \mathrm{P}_{3} \mathrm{O}_{16.5}$. $\mathrm{xH}_{2} \mathrm{O}$, become weaker after the heat treatment. However, a different scenario occurs in $85 \mathrm{RH}$ sample. Although the Bragg peaks of $\mathrm{H}_{4} \mathrm{~V}_{3} \mathrm{P}_{3} \mathrm{O}_{16.5} \cdot \mathrm{xH}_{2} \mathrm{O}$ crystals become weaker after heat treatment, other sharp Bragg peaks emerge owing to the formation of $\mathrm{VO}\left(\mathrm{HPO}_{4}\right) \cdot \mathrm{xH}_{2} \mathrm{O}(\mathrm{JCPDS} 44-0598)$ crystals. This implies that the exothermic peaks at about $700 \mathrm{~K}$ of both $65 \mathrm{RH}$ and $85 \mathrm{RH}$ samples could arise from the crystal transformation via an intermediate amorphous process. In addition, according to the XRD patterns of $85 \mathrm{RH}$, some other types of crystals in addition to $\mathrm{H}_{4} \mathrm{~V}_{3} \mathrm{P}_{3} \mathrm{O}_{16.5} \cdot \mathrm{xH}_{2} \mathrm{O}$ might already 
exist, but their identities are missing due to the smaller sizes at that moment (Fig. 1a). It is likely that these crystals are $\mathrm{VO}\left(\mathrm{HPO}_{4}\right) \cdot \mathrm{xH}_{2} \mathrm{O}$, which grow to larger crystals during heat treatment.

\subsection{Electrochemical performances}
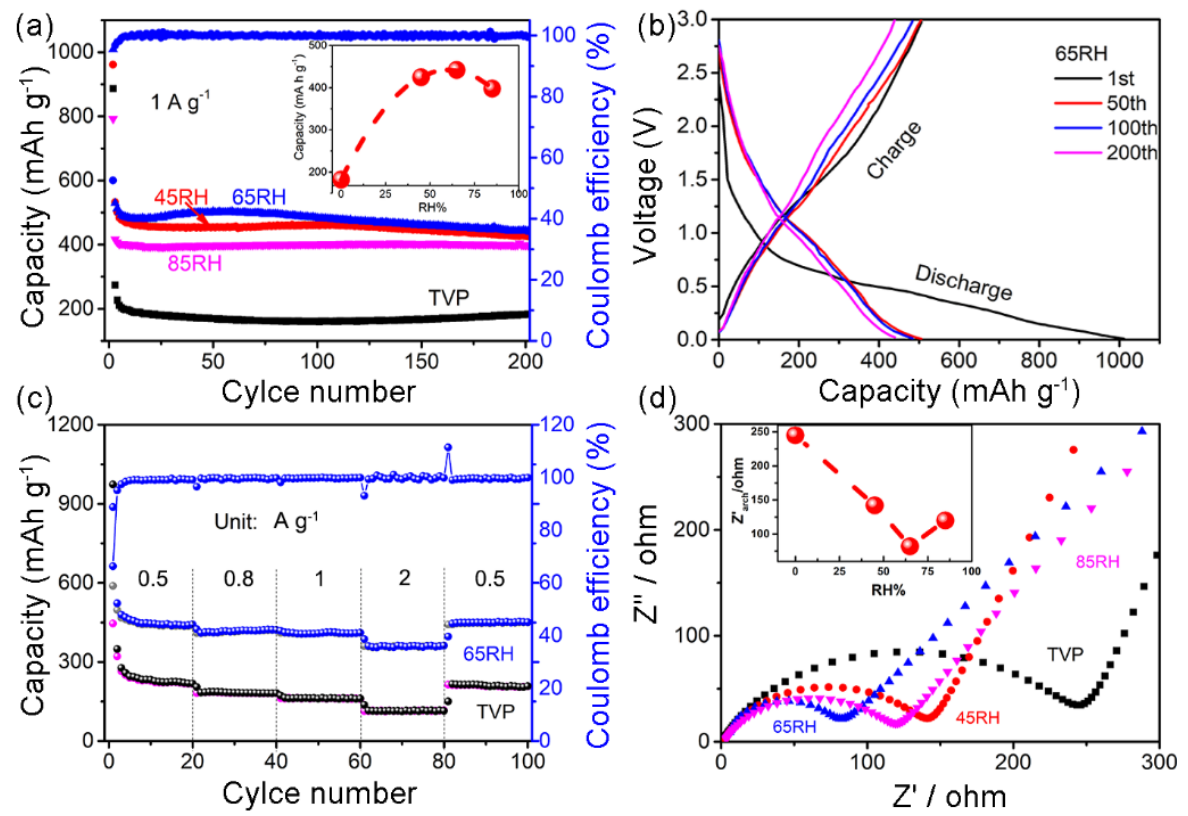

Fig. 3. Electrochemical performances. (a) Cycling performance of the 'dry' TVP, 45RH, 65RH and 85RH anodes at a current density of $1 \mathrm{~A} \mathrm{~g}^{-1}$, and the corresponding $\mathrm{CE}$ of $65 \mathrm{RH}$. Inset: the specific capacity of the samples after 200 cycles as a function of the treated relative humidity. (b) Galvanostatic charge/discharge voltage profiles of 65RH. (c) Rate capability comparison between the 'dry' TVP and 65RH anodes. (d) Nyquist plot at the open-circuit potential of the 'dry' TVP, 45RH, $65 \mathrm{RH}$ and $85 \mathrm{RH}$ anodes. Inset: the internal ohmic resistance reflected by the diameter of the semicircle as a function of the treated relative humidity.

To investigate the effect of the incorporated water on the electrochemical performances of TVP glass anode, a systematic study was carried out to compare the lithium-ion storage properties of the water-modified glass-based anodes with those of the "dry" sample. Fig. 3a shows the cycling 
performances of the 'dry' TVP, 45RH, 65RH and $85 \mathrm{RH}$ anodes at a current density of $1 \mathrm{~A} \mathrm{~g}^{-1}$, respectively. Although the TVP anode is stable during the repeated lithiation/delithiation process, the active sites are not sufficient, and the ionic conductivity is low, leading to a relatively low specific capacity of $182 \mathrm{~mA} \mathrm{~h} \mathrm{~g}^{-1}$ after 200 cycles. In strong contrast, the capacities of the hydrated samples, i.e., 45RH, 65RH and 65RH, reach astonishing values of 425, 442 and $398 \mathrm{~mA} \mathrm{~h} \mathrm{~g}^{-1}$ after 200 cycles (the inset in Fig. 3a), which are two times higher than that of the 'dry' TVP anode. The dramatically boosted capacity must be due to the fact that the incorporated water alters the microstructure of the TVP sample, and thereby increases the structural stability and the ionic conductivity, as well as generates numerous active sites. These factors enable fast reaction, leading to the synergetic enhancement of capacity and cycling performance of the hydrated samples. Note that the discharge capacity of the $85 \mathrm{RH}$ decreased a bit compared to that of $65 \mathrm{RH}$ but still much larger than that of 'dry' TVP anode. Moreover, the Coulombic efficiency (CE) of 65RH sample increases rapidly from the second cycle to $99 \%$. The high CE implies the enhancement of the effective availability of lithium species, thus the superior reversible capacity.

To further evaluate the specific capacity of the hydrated samples, galvanostatic charge/discharge voltage profiles were collected on $65 \mathrm{RH}$ as displayed in Fig. $3 \mathrm{~b} .65 \mathrm{RH}$ anode exhibits the initial discharge/charge capacities of 1011/506 $\mathrm{mA} \mathrm{h} \mathrm{g}^{-1}$ at $1 \mathrm{~A} \mathrm{~g}^{-1}$, corresponding to an initial CE of 50.0\%. The irreversible capacity mainly comes from the irreversible reactions of the inserted $\mathrm{Li}^{+}$ions with the glass anodes [26] and the formation of solid electrolyte interface (SEI). In the following 50, 100 and 200 cycles, the voltage profiles share almost the same shape and the specific capacities decreases only slightly, such as 505, 484 and $440 \mathrm{~mA} \mathrm{~h} \mathrm{~g}^{-1}$, respectively, confirming the reversibility of the 
lithium storage reaction at a high current density.

Rate capability is one of the most important parameters to evaluate the high-power delivery capability of LIBs. The rate capabilities of both 'dry' TVP and 65RH were determined by altering current densities (Fig. 3c). The 65RH delivers a reversible capacity of $442 \mathrm{~mA} \mathrm{~h} \mathrm{~g}^{-1}$ at $0.5 \mathrm{~A} \mathrm{~g}^{-1}$. When the current density is increased to 0.8 , and $1 \mathrm{~A} \mathrm{~g}^{-1}$, the specific capacities slightly drop to 417 and 409 $\mathrm{mA} \mathrm{h} \mathrm{g}^{-1}$, respectively. Even at a high current density of $2 \mathrm{~A} \mathrm{~g}^{-1}$, the anode still maintains a reversible capacity of $360 \mathrm{~mA} \mathrm{~h} \mathrm{~g}^{-1}$, corresponding to $81.5 \%$ of the initial one, which significantly exceeds the value $\left(208 \mathrm{~mA} \mathrm{~h} \mathrm{~g}^{-1}\right)$ of the 'dry' TVP based anode. As the current density is returned to $0.5 \mathrm{~A} \mathrm{~g}^{-1}$, the capacity of $65 \mathrm{RH}$ based anode swiftly restores to the value of $451 \mathrm{~mA} \mathrm{~h} \mathrm{~g}^{-1}$ as high as the initial capacity. Compared with the 'dry' TVP, 65RH exhibits a superior rate capability when the current density is increased from 0.5 to $2 \mathrm{~A} \mathrm{~g}^{-1}$ and then returns to $0.5 \mathrm{~A} \mathrm{~g}^{-1}$. The high-rate capability as well as the excellent recovery performance are crucial for the practical applications of LIB anodes.

The electrochemical kinetics at the electrode/electrolyte interface can be revealed by the electrochemical impedance spectroscopy (EIS) analysis as seen in Fig. 3d. The EIS exhibits similar Nyquist plot, i.e., one depressed semicircle followed by an inclined line related to $\mathrm{Li}^{+}$diffusion in the bulk electrode [43]. The semicircle is related to the charge-transfer resistance and the intercept of the semicircle represents the internal ohmic resistance of the electrode. For the 'dry' TVP sample, the resistance is relatively high because of the poor conductivity. After the humidity treatment, there is a remarkable decrease in the charge transfer resistance, and thus an apparent reduction in battery impedance, especially for $65 \mathrm{RH}$ (seen in the inset of Fig. 3d), indicating the overall smallest resistance of charge transfer and a more-facile transfer of $\mathrm{Li}^{+}$ions at the $65 \mathrm{RH}$ anode/electrolyte 
interface. The improvement is attributed to the unique effect of the incorporated water on altering the $3 \mathrm{D}$ network structure of $65 \mathrm{RH}$, which increases efficient channels for transportation of $\mathrm{Li}^{+}$ions and electrons.

To gain further insight into the reaction kinetics of both the dry and the hydrated glass-based anodes, we performed CV measurements on the 'dry' and the $65 \mathrm{RH}$ samples within the window of $0.01 \sim 3.0$ $\mathrm{V}$ at different scan rates from 0.1 to $2 \mathrm{mV} \mathrm{s}^{-1}$ (Figs. $4 \mathrm{a}$ and $\mathrm{b}$ ). This is one of the effective approaches to investigate the electrochemical reaction kinetics of electrode materials for $\mathrm{Li}^{+}$storage $[44,45]$. A recent study revealed that the capacity generation of a silicate glass-ceramic anode involves two lithium-ion storage mechanisms [46]. One is the lithium insertion reaction, while the other is related to both ion diffusion and surface induced capacitance. In the present work, we determine the degree of surface induced capacitive effect of the studied anodes using the relationship between the measured current $(i)$ and sweep rate $(v)$ of the CV curves, i.e., $i=a v^{b}$, where $a$ and $b$ are adjustable parameters. The $b$ value is in the range between 0.5 and 1.0. The $b$ value of 0.5 implies a diffusion-controlled process. The totally stored charge comes from lithium insertion process. In contrast, $b=1$ suggests an ideally capacitance-controlled process, which takes place mostly on the surface of electrode [47]. A value between 0.5 and 1 implies the mixed contribution from both the diffusion-controlled process and the capacitive effect. In Figs. $4 \mathrm{a}$ and $\mathrm{b}$, the $\mathrm{CV}$ curves of the dry and 65RH samples show that both the potential difference of the redox peaks and the peak current increase with increasing the scan rate. As demonstrated in Fig. 4c, the currents of the five pairs of cathodic/anodic peaks for TVP anode show a linear dependence on square root of the scan rate. The $b$ values for the cathodic and anodic scans are determined to be 0.69 and 0.71 , respectively, revealing that the capacity of TVP anode arises 
from both diffusion-controlled reactions and surface-controlled processes. However, as shown in Fig. $4 \mathrm{~d}$, the $b$ values for $65 \mathrm{RH}$ anode are 0.88 and 0.90 for the cathodic and anodic scans, respectively, indicating that the electrochemical lithium storage in $65 \mathrm{RH}$ is governed by both diffusion-controlled processes and the capacitive effect, especially a predominant contribution from surface-controlled redox reactions, i.e., the pseudocapacitive behavior.

In addition, the $\mathrm{CV}$ curve (the current response $i$ at specific potentials $V$ ) can be separated into two contributions including the surface induced capacitance $\left(k_{1} v\right)$ and diffusion-controlled processes $\left(k_{2} v^{1 / 2}\right)$ as described in the following equation [48,49]:

$$
i=k_{1} v+k_{2} v^{1 / 2}
$$

where $v$ is scan rate, both $k_{1}$ and $k_{2}$ are parameters. In Fig. $4 \mathrm{e}$, the fraction of charge stored arising from capacitive processes of $65 \mathrm{RH}$ sample is determined to be $51 \%$ at a scan rate of $0.1 \mathrm{mV} \mathrm{s}^{-1}$. As the scan rate increases to $0.2,0.5,1$ and $2 \mathrm{mV} \mathrm{s}^{-1}$, the capacitive contributions are $59 \%, 68 \%, 64.8 \%$, $75 \%$, and $83 \%$, respectively (Fig. $4 \mathrm{f}$ ), suggesting the capacitive-dominant characteristics at high-rate conditions. This phenomenon could be ascribed to the nanocrystals induced by the incorporated water with a large surface area, which provides extra active sites for lithiation/delithiation through the capacitive process. Such a prominent contribution by capacitive lithium storage not only gives $65 \mathrm{RH}$ a superior high-rate capability, but also improves its cycling stability and high rates capability. 

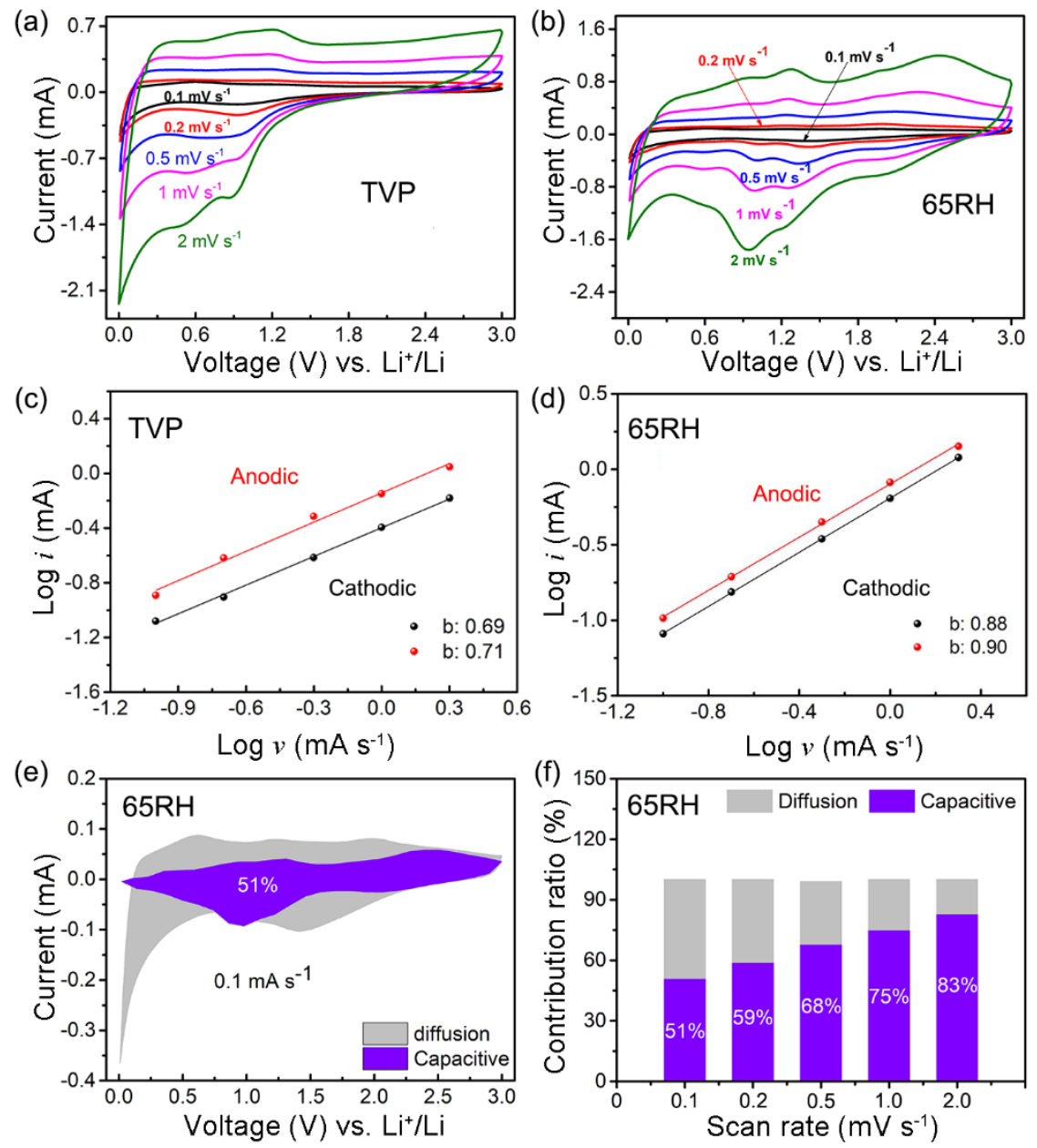

Fig. 4. CV curves of (a) TVP and (b) 65RH anodes at various scan rates from 0.1 to $2 \mathrm{mV} \mathrm{s}^{-1} . b$ values determined from cathodic and anodic peaks with scan rate from 0.1 to $2 \mathrm{mV} \mathrm{s}^{-1}$ for (c) TVP and (d) $65 \mathrm{RH}$ anode. (e) Separation of the capacitive and diffusion-controlled capacity contribution at $0.1 \mathrm{mV} \mathrm{s}^{-1}$. (f) Contribution ratio of capacitive- and diffusion-controlled capacities at various scan rates $(0.1,0.2,0.5,1$, and $\left.2 \mathrm{mV} \mathrm{s}^{-1}\right)$

To clarify the reasons for the booming capacities of the hydrous samples, XPS was employed to probe the chemical states of the components, especially the $\mathrm{OH}$ species, in the four sample before cycles. The O 1s high-resolution XPS spectra of the four samples are displayed in Fig. 5a, where the broad and asymmetric peak of each sample can be deconvoluted into three peaks, revealing the 
presence of at least three distinct oxygen species. Notably, the peak at $533.1 \mathrm{eV}$ is associated with the crystal water in the precipitated $\mathrm{H}_{4} \mathrm{~V}_{3} \mathrm{P}_{3} \mathrm{O}_{16.5} \cdot \mathrm{xH}_{2} \mathrm{O}$, i.e., the molecularly adsorbed $\mathrm{H}_{2} \mathrm{O}$ [50-52]. The peak at $531.5 \mathrm{eV}$ corresponds to the $-\mathrm{OH}$ groups [33]. It is evident that the areas of the two peaks in the hydrated samples expand dramatically with increasing relative humidity, suggesting that more $\mathrm{H}_{2} \mathrm{O}$ and $-\mathrm{OH}$ groups reside in the samples. This result is consistent with the observation on TGA, i.e., the structural $\mathrm{H}_{2} \mathrm{O}$ including the $\mathrm{OH}$ species could be incorporated into the network structure of glass matrix. Thus, it is reasonable to infer that the incorporated $\mathrm{H}_{2} \mathrm{O}$ might contribute greatly to the boosted capacity of TVP glass after the hydration treatment.
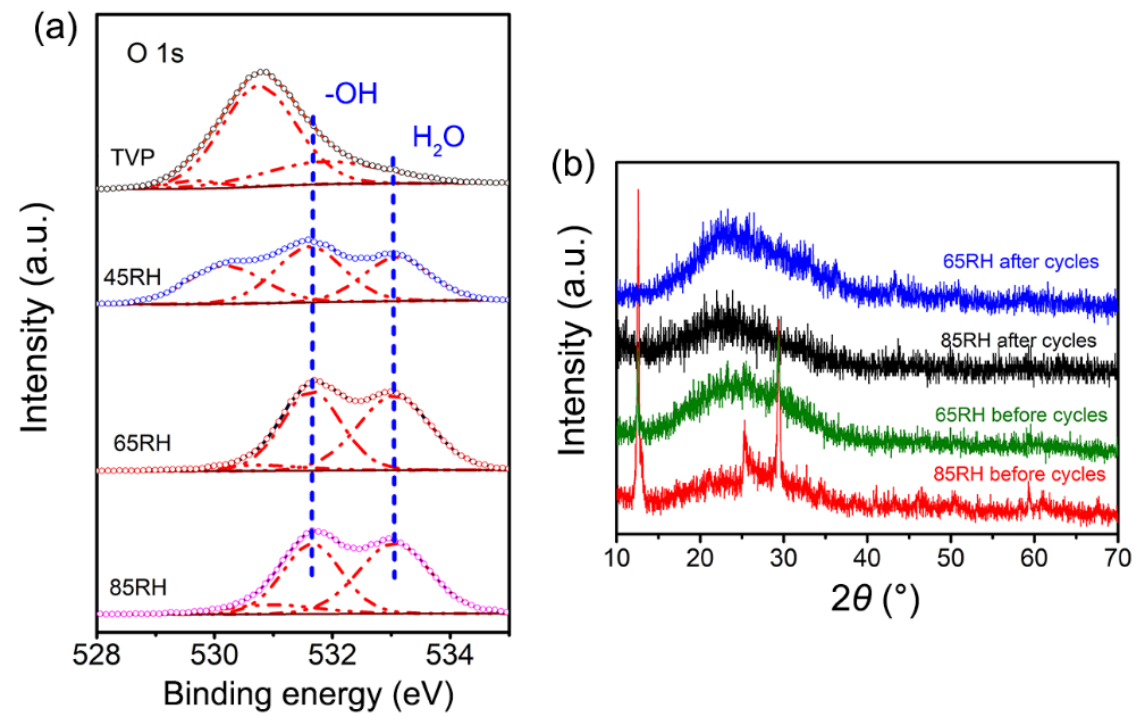

Fig. 5. (a) O 1s core level XPS spectra of the TVP, 45RH, 65RH and 85RH samples. (b) XRD patterns of both $65 \mathrm{RH}$ and $85 \mathrm{RH}$ samples before and after 200 cycles.

Fig. $5 \mathrm{~b}$ shows the XRD patterns of the $65 \mathrm{RH}$ and $85 \mathrm{RH}$ samples before and after 200 cycles at 1 $\mathrm{A} \mathrm{g}^{-1}$, respectively. It is seen that the Bragg peaks in the XRD pattern of the $65 \mathrm{RH}$ and $85 \mathrm{RH}$ disappeared, instead, a hump was observed in the patterns of the samples after cycles. This means that the nanocrystals induced by humidity treatment were transformed into amorphous domain, i.e., 
experienced an order-disorder transition, during discharge/charge cycles.

From the above analyses, it can be stated that the incorporated - $\mathrm{OH}$ species, which keep stable during cycling, in TVP glass is the decisive factor for the substantially boosted electrochemical performances of the glass anodes (Fig. S2). In a recent study, it was found the -OH groups were responsible for the improved cycle life and reversible capacity of electrodeposited films of bilayered vanadium oxide $\left(\mathrm{EC}-\mathrm{V}_{2} \mathrm{O}_{5}\right)$ relative to the sol-gel derived $\mathrm{V}_{2} \mathrm{O}_{5}$ phases [33]. In addition, it was also found that a moderate amount of lattice water in $\mathrm{K}_{0.77} \mathrm{MnO}_{2} \cdot 0.23 \mathrm{H}_{2} \mathrm{O}$ electrode can act as pillars to stabilize the expanded interlayer region required for fast $\mathrm{K}^{+}$ion diffusion, thus leading to high electrochemical performance of $\mathrm{K}$-ion batteries [53]. This implies that the incorporated water, in particular the $-\mathrm{OH}$ species, along with the disordered domains and the ordered structures in the hydrated sample synergistically contributed to the boosted capacities.

Considering above thermodynamic and structural analysis, the significantly enhanced reversible capacity and rate capabilities of hydrated TVP anode, especially $65 \mathrm{RH}$, could be attributed to its unique and favorable reconstructed architecture by the incorporated water. As is known, the primary way for water incorporation into the network of phosphate glass is formation of $\mathrm{P}-\mathrm{OH}$ groups, similar to alkali-metal oxide modifiers, resulting in depolymerization of structural network $[54,55]$. The structural $-\mathrm{OH}$ species in $45 \mathrm{RH}, 65 \mathrm{RH}$ and $85 \mathrm{RH}$ samples are stable and maintain a sufficient interlayer spacing to allow the diffusion of $\mathrm{Li}^{+}$ions over multiple cycles [56]. This is the main reason for the improved electrochemical performances. Furthermore, the nanocrystals, which form through hydration, can greatly shorten the $\mathrm{Li}^{+}$ions diffusion paths and the reconstructed surfaces of the nanocrystals provide more active sites for lithium storage. The remaining glass matrix can efficiently 
accommodate the large volume changes during cycles. Thus, the humidity treatment is a powerful strategy to modify the network structure of the glass and thereby to promote the $\mathrm{Li}^{+}$ions diffusion and to create more active sites for lithiation/delithiation.

\section{Conclusions}

In summary, we established the humidity treatment strategy to greatly improve the electrochemical performances of the $\mathrm{TeO}_{2}-\mathrm{V}_{2} \mathrm{O}_{5}-\mathrm{P}_{2} \mathrm{O}_{5}$ (TVP) glass anodes for LIBs. Remarkably, this strategy led to a significant enhancement of the reversible capacity in TVP glass anode, e.g., from 182 to $442 \mathrm{~mA} \mathrm{~h}$ $\mathrm{g}^{-1}$ at $1 \mathrm{~A} \mathrm{~g}^{-1}$ upon 200 cycles for TVP glass subjected to the $65 \%$ humidity treatment for $120 \mathrm{~h}$ at 333 K. This strategy also gives rise to the capacity retention of nearly $100 \%$ after 200 cycles at high current density. The incorporated -OH in TVP glass may cause the following aspects such as broadening of the network channels for $\mathrm{Li}^{+}$diffusion and increasing active sites for lithium storage. The hydration-induced nanocrystals feature specific surface area, thus providing more reaction sites. The optimum humidity for enhancing the anode performances was further verified by experimental results. This study brought a new, simple and economically effective approach for developing superior glass anodes for LIBs.

\section{CRediT authorship contribution statement}

Zhenjing Jiang: Methodology, Investigation, Data curation, Writing - original draft. Shibin Qi: Methodology, Investigation, Data curation. Chengwei Gao: Data curation. Xiangyu Li: Data curation. Yanfei Zhang: Supervision, Methodology, Investigation, Writing - review \& editing. Yuanzheng Yue: Supervision, Methodology, Investigation, Writing - review \& editing. 


\section{Declaration of Competing Interest}

The authors declare that they have no known competing financial interests or personal relationships that could have appeared to influence the work reported in this paper.

\section{Acknowledgments}

This work was financially supported by Taishan Youth Scholar Project of Shandong Province (tsqn202103098), Shandong Provincial Natural Science Foundation (ZR2020ME025), the Colleges and Universities Twenty Terms Foundation of Jinan City (2019GXRC034) and Foundation from State Key Laboratory of Special Glass of China.

\section{Appendix A. Supplementary data}

Supplementary data to this article can be found online at $\mathrm{xxx}$.

\section{References}

[1] Y. Zhang, P. Wang, T. Zheng, D. Li, G. Li, Y. Yue, Enhancing Li-ion battery anode performances via disorder/order engineering, Nano Energy 49 (2018) 596-602.

[2] X. Wu, S. Zhao, L. Yu, E. Zhao, C. Nan, Lithium storage behavior of $\mathrm{MoO}_{3}-\mathrm{P}_{2} \mathrm{O}_{5}$ glass as cathode material for Li-ion batteries, Electrochimi. Acta 297 (2019) 872-878.

[3] S. Choi, S. Lee, H. Kim, S. Park, J. Choi, $\mathrm{Li}_{2} \mathrm{O}-\mathrm{B}_{2} \mathrm{O}_{3}-\mathrm{GeO}_{2}$ glass as a high performance anode material for rechargeable Lithium-ion batteries, J. Mater. Chem. A 6 (2018) 6860-6866.

[4] S. Gandi, S. Chinta, P. Ghoshal, B. Ravuri, $\mathrm{SnO}-\mathrm{GeO}_{2}-\mathrm{Sb}_{2} \mathrm{O}_{3}$ glass anode network mixed with different $\mathrm{Ba}^{2+}$ fractions: investigations on Na-ion storage capacity and stability, J. Non-cryst. Solids 
506 (2019) 80-87.

[5] A. Semih, K. Frank, M. Christian, B. Andreas, N. Reinhard, New high capacity cathode materials for rechargeable Li-ion batteries: Vanadate-Borate glasses, Scientific Reports 4 (2014) 7113.

[6] W. He, X. Zhang, C. Jin, S. Mossin, Y. Yue, Nano-glass ceramic cathodes for $\mathrm{Li}^{+} / \mathrm{Na}^{+}$Mixed-ion batteries, J. Power Sources 342 (2017) 717-725.

[7] L. Yu, S. Zhao, X. Wu, E. Zhao, G. Wei, Lithium ion storage behaviors of $(100-\mathrm{x}) \mathrm{V}_{2} \mathrm{O}_{5}-(\mathrm{x}) \mathrm{P}_{2} \mathrm{O}_{5}$ glass as novel anode materials for Lithium Ion Battery, J. Alloys Compd. 810 (2019) 151938.

[8] Y. Idota, T. Kubota, A. Matsufuji, Y. Maekawa, T. Miyasaka, Tin-based amorphous oxide: a highcapacity Lithium-ion-storage material, Science 276 (1997) 1395-1397.

[9] A. Hayashi, M. Nakai, H. Morimoto, T. Minami, M. Tatsumisago, Mechanochemical synthesis of $\mathrm{SnO}-\mathrm{B}_{2} \mathrm{O}_{3}$ glassy anode materials for rechargeable Lithium batteries, J. Mater. Sci. 39 (2004) 53615364.

[10] H. Morimoto, M. Nakai, M. Tatsumisagoz, T. Minami, Mechanochemical synthesis and anode properties of SnO-based amorphous materials, J. Electrochem. Soc. 146 (1999) 3970-3973.

[11] X. Wang, W. Han, H. Chen, X. Wang, X. Yang, Amorphous hierarchical porous $\mathrm{GeO}_{\mathrm{x}}$ as highcapacity anodes for Li ion batteries with very long cycling life, J. Am. Chem. Soc. 133 (2011) 2069220695.

[12] H. Kondo, T. Honma, T. Komatsu, Synthesis and morphology of metal Sn particles in $\mathrm{SnO}-\mathrm{P}_{2} \mathrm{O}_{5}$ glasses and their battery anode performance, J. Non-cryst. Solids 402 (2014) 153-159. 
[13] H. Zhou, D. Li, M. Hibino, I. Honma, A self-ordered, crystalline-glass, mesoporous nanocomposite for use as a Lithium-based storage device with both high power and high energy densities, Angew. Chem. Int. Ed. 44 (2005) 797-802.

[14] Y. Zhang, P. Wang, G. Li, J. Fan, Y. Yue, Clarifying the charging induced nucleation in glass anode of Li-ion batteries and its enhanced performances, Nano Energy 57 (2019) 592-599.

[15] J. Fan, Y. Zhang, G. Li, Y. Yue, Tellurium nanoparticles enhanced electrochemical performances of $\mathrm{TeO}_{2}-\mathrm{V}_{2} \mathrm{O}_{5}-\mathrm{Al}_{2} \mathrm{O}_{3}$ glass anode for Lithium-ion batteries, J. Non-Cryst. Solids 521 (2019) 119491.

[16] I. Son, J. Park, S. Kwon, S. Doo, H. Chang, Silicon carbide-free graphene growth on silicon for Lithium-ion battery with high volumetric energy density, Nat. Commun. 6 (2015) 7393.

[17] K. J. Griffith, K. M. Wiaderek, G. Cibin, Niobium tungsten oxides for high-rate Lithium-ion energy storage, Nature 559 (2018) 556-563.

[18] S. Thonglem, G. Rujijanagul, S. Eitssayeam, T. Tunkasiri, K. Pengpat, Fabrication of $\mathrm{P}_{2} \mathrm{O}_{5}-\mathrm{CaO}-$ $\mathrm{Na}_{2} \mathrm{O}$ glasses doped with magnesium oxide for artificial bone applications, Ceram. Int. 39 (2013) 537-540.

[19] Y. Fu, J. K. Christie, Atomic structure and dissolution properties of Yttrium containing Phosphate glasses, Int J Appl Glass Sci. 8 (2017) 412-417.

[20] F. Baino, G. Novajra, V. Miguez-Pacheco, A. R. Boccaccini, C. Vitale-Brovarone, Bioactive glasses: special applications outside the skeletal system, J. Non-Cryst. Solids 432 (2016) 15-30.

[21] T. Wei, Y. Hu, L. G. Hwa, Structure and elastic properties of low-temperature sealing Phosphate 
glasses, J. Non-Cryst. Solids 288 (2001) 140-147.

[22] J. Hong, D. Zhao, J. Gao, M. He, G. He, Lead-free low-melting point sealing glass in SnO-CaO$\mathrm{P}_{2} \mathrm{O}_{5}$ system, J. Non-Cryst. Solids 356 (2010) 1400-1403.

[23] J. Juarez-Batalla, A. N. Meza-Rocha, G. Muñoz, H.I. Camarillo, U. Caldino, Luminescence properties of $\mathrm{Tb}^{3+}$-doped Zinc Phosphate glasses for green laser application, Opt. Mater. 58 (2016) 406-411.

[24] A. S. Pinheiro, Z. M. D. Costa, M. J. V. Bell, V. Anjos, S. T. Reis, Thermal characterization of Iron Phosphate glasses for nuclear waste disposal, Opt. Mater. 33 (2011) 1975-1979.

[25] S. S. Das, N. P. Singh, P. K. Srivastava, Ion conducting Phosphate glassy materials, Prog. Cryst, Growth Charact. Mater., 55 (2009) 47-62.

[26] Z. Jiang, T. Zhao, J. Ren, Y. Zhang, Y. Yue, NMR evidence for the charge-discharge induced structural evolution in a Li-ion battery glass anode and its impact on the electrochemical performances, Nano Energy 80 (2020) 105589.

[27] R. K. Brow, C. A. Click, T. M. Alam, Modifier coordination and Phosphate glass networks, J. Non-Cryst. Solids 274 (2000) 9-16.

[28] S. Sirotkin, R. Meszaros, L. Wondraczek, Chemical stability of $\mathrm{ZnO}-\mathrm{Na}_{2} \mathrm{O}-\mathrm{SO}_{3}-\mathrm{P}_{2} \mathrm{O}_{5}$ glasses, Int. J. Appl. Glass Sci. 3 (2012) 44-52.

[29] B. C. Bunker, G. W. Arnold, J. A. Wilder, Phosphate glass dissolution in aqueous solutions, J. Non-Cryst. Solids 64 (1984) 291-316. 
[30] A. A. Ahmed, A. A. Ali, D. Mahmoud, A. El-Fiqi, Preparation and characterization of antibacterial $\mathrm{P}_{2} \mathrm{O}_{5}-\mathrm{CaO}-\mathrm{Na}_{2} \mathrm{O}-\mathrm{Ag}_{2} \mathrm{O}$ glasses, J. Biomed. Mater. Res. A 98A (2011) 132-142.

[31] C. M. Jantzen, Systems approach to nuclear waste glass development, J. Non. Cryst. Solids 84, (1986) 215-225.

[32] J. E. Mendel, The Storage and Disposal of Radioactive Waste as Glass in Canisters, Pacific Northwest Laboratory, Washington, 1978, pp. 27-31.

[33] S. Tepavcevic, J. Connell, P. Lopes, M. Bachhav, N. Markovic, Role of structural hydroxyl groups in enhancing performance of electrochemically-synthesized bilayer $\mathrm{V}_{2} \mathrm{O}_{5}$, Nano Energy 53 (2018) 449-457.

[34] J. Mitchell, W. Lo, A. Genc, J. LeBeau, V. Augustyn, Transition from battery to pseudocapacitor behavior via structural water in Tungsten oxide, Chem. Mater. 29 (2017) 928-3937.

[35] T. Yamaguchi, Y. Saito, Y. Kuwahara, H. Yamashita, T. Omata, Effect of Alkaline-earth species in Phosphate glasses on the mobility of proton carriers, J. Mater. Chem. A 5 (2017) 12385-12392.

[36] A. Miyazaki, T. Kinoshita, T. Tatebayashi, T. Fang, J. Nishii, Thermal stability and proton conductivity of densely proton injected Phosphate glasses containing Rare-earth elements, J. NonCryst. Solids 541 (2020) 120064.

[37] T. Yamaguchi, T. Kataoka, S. Tsukuda, T. Ishiyama, T. Omata, The mobility of proton carriers in Phosphate glasses depends on polymerization of the phosphate framework, Phys. Chem. Chem. Phys. 19 (2017) 29669-29675. 
[38] T. Ishiyama, J. Nishii, T. Yamashita, H. Kawazoe, T. Omata, Electrochemical substitution of Sodium ions with protons in Phosphate glass to fabricate pure proton conducting glass at intermediate temperatures, J. Mater. Chem. A 2 (2014) 3940-3947.

[39] S. Naseri, W. Lepry, W. Li, A. Boccaccini. S. Nazhat, 45S5 bioactive glass reactivity by dynamic vapour sorption, J. Non-Cryst. Solids 432 (2016) 47-52.

[40] K. Nakamoto, Infrared and Raman Spectra of Inorganic and Coordination Compounds (third eds), Wiley, New York, 1978, pp. 448.

[41] T. Tran, S. Turrell, M. Eddafi, B. Capoen, C. Kinowski, Investigations of the effects of the growth of $\mathrm{SnO}_{2}$ nanoparticles on the structural properties of glass-ceramic planar waveguides using Raman and FTIR spectroscopies, J. Mol. Struct. 976 (2010) 314-319.

[42] D. Rébiscoul, F. Bruguier, V. Magnin, S. Gin, Impact of Soda-lime Borosilicate glass composition on water penetration and water structure at the first time of alteration, J. Non-Cryst. Solids 358 (2012) 2951-2960.

[43] X. Chen, N. Zhang, K. Sun, Facile fabrication of $\mathrm{CuO}$ mesoporous nanosheet cluster array electrodes with super Lithium-storage properties, J. Mater. Chem. 22 (2012) 13637-13642.

[44] C. Chen, Y. Wen, X. Hu, X. Ji, Y. Huang, $\mathrm{Na}^{+}$intercalation pseudocapacitance in Graphenecoupled Titanium oxide enabling ultra-fast Sodium storage and long-term cycling, Nat. Commun. 6 (2015) 6929.

[45] B. K. Lesel, J. B. Cook, Y. Yan, T. C. Lin, S. H. Tolbert, Using nanoscale domain size to control charge storage kinetics in pseudocapacitive nanoporous $\mathrm{LiMn}_{2} \mathrm{O}_{4}$ powders, ACS Energy Lett 2 (2017) 
2293-2298.

[46] S. Liu, W. Tang, J. Ma, Y. Zhang, Y. Yue, $\mathrm{Li}_{2} \mathrm{TiSiO}_{5}$ glass ceramic as anode materials for highperformance Lithium-ion batteries, ACS Appl. Energy Mater. 3 (2020) 9760-9768.

[47] V. Augustyn, J. Come, M. A. Lowe, J. W. Kim, B. Dunn, High-rate electrochemical energy storage through $\mathrm{Li}^{+}$intercalation pseudocapacitance, Nat. Mater. 12 (2013) 518-522.

[48] E. Lim, C. Jo, H. Kim, M. H. Kim, J. Lee, Facile synthesis of $\mathrm{Nb}_{2} \mathrm{O}_{5} @$ Carbon core-shell nanocrystals with controlled crystalline structure for high-power anodes in hybrid supercapacitors, ACS Nano, 9 (2015) 7497-7505.

[49] E. Lim, C. Jo, M. S. Kim, M. H. Kim, J. Lee, High - performance Sodium - ion hybrid supercapacitor based on $\mathrm{Nb}_{2} \mathrm{O}_{5} @$ Carbon core-shell nanoparticles and reduced Graphene oxide nanocomposites, Adv. Funct. Mater. 26 (2016) 3711.

[50] X. Zhang, S. Ptasinska, Dissociative adsorption of water on an $\mathrm{H}_{2} \mathrm{O} / \mathrm{GaAs}(100)$ interface: in situ near-ambient pressure XPS studies, J. Phys. Chem. C 118 (2014) 4259-4266.

[51] Z. Wei, M. Liu, Z. Zhang, W. Yao, Y. Zhu, Efficient visible-light-driven selective Oxygen reduction tohydrogen peroxide by oxygen-enriched Graphitic Carbon Nitride polymers, Energy Environ. sci. 11 (2018) 2581-2589.

[52] L. O. Mahony, T. Curtin, D. Zemlyanov, M. Mihov, B. K. Hodnett, Surface species during the crystallization of $\mathrm{VOHPO}_{4} \cdot 0.5 \mathrm{H}_{2} \mathrm{O}$, J. Catal. 227 (2004) 270-281.

[53] B. Lin, X. Zhu, L. Fang, X. Liu, H. Xia, Birnessite nanosheet arrays with high K content as a 
high-capacity and ultrastable cathode for K-ion batteries, Adv. Mater. 31 (2019) 1900060.

[54] T. I. Suratwala, R. A. Steele, G. D. Wilke, J. H. Campbell, K. Takeuchi, Effects of OH content, water vapor pressure, and temperature on sub-critical crack growth in Phosphate glass, J. Non-Cryst. Solids 263\&264 (2000) 213-227.

[55] R. M. Wenslow, K. T. Mueller, Structural details of aqueous attack on a Phosphate glass by ${ }^{1} \mathrm{H} /{ }^{31} \mathrm{P}$ cross-polarization NMR, J. Phys. Chem. B 102 (1998) 9033-9038.

[56] S. Mizusaki, Y. Toyoda, K. Nakayama, Y. Nagata, H. Samata, Catalysis and proton-conduction of novel Phosphate glasses, J. Non-Cryst. Solids 355 (2009) 960-964. 


\section{Supplement Information}

\section{Water Boosts the Performances of Glass Anodes for Lithium-Ion}

\section{Batteries}

Zhenjing Jianga ${ }^{\mathrm{a}, 1}$, Shibin $\mathrm{Qi}^{\mathrm{a}, 1}$, Chengwei Gao ${ }^{\mathrm{b}}$, Xiangyu $\mathrm{Li}^{\mathrm{a}}$, Yanfei Zhang ${ }^{\mathrm{a},{ }^{*}}$, Yuanzheng

$$
\text { Yue }^{\text {b,* }}
$$

${ }^{a}$ School of Materials Science and Engineering, Qilu University of Technology (Shandong Academy of Sciences), Jinan 250353, China

${ }^{\mathrm{b}}$ Department of Chemistry and Bioscience, Aalborg University, 9220 Aalborg, Denmark

${ }^{1}$ These authors contributed equally to this work.

* Corresponding Authors: E-mail: zhang-yanfei@hotmail.com (Y.Z.); yy@bio.aau.dk (Y.Y.)

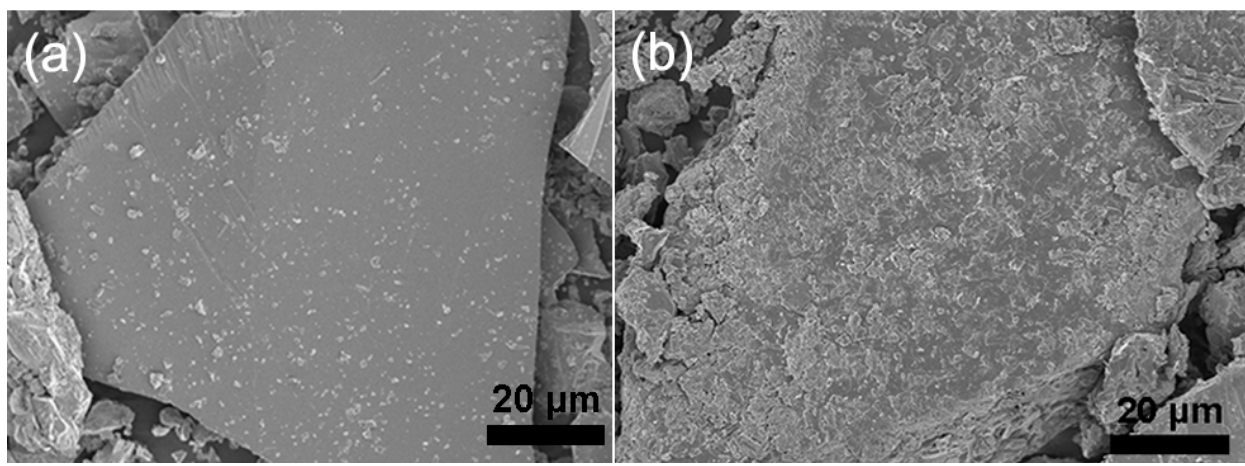

Fig.1. SEM images of (a) and (b) TVP and 65RH samples, demonstrating the eroded surface of the TVP glass powders by the incorporated water during humidity treatment. 


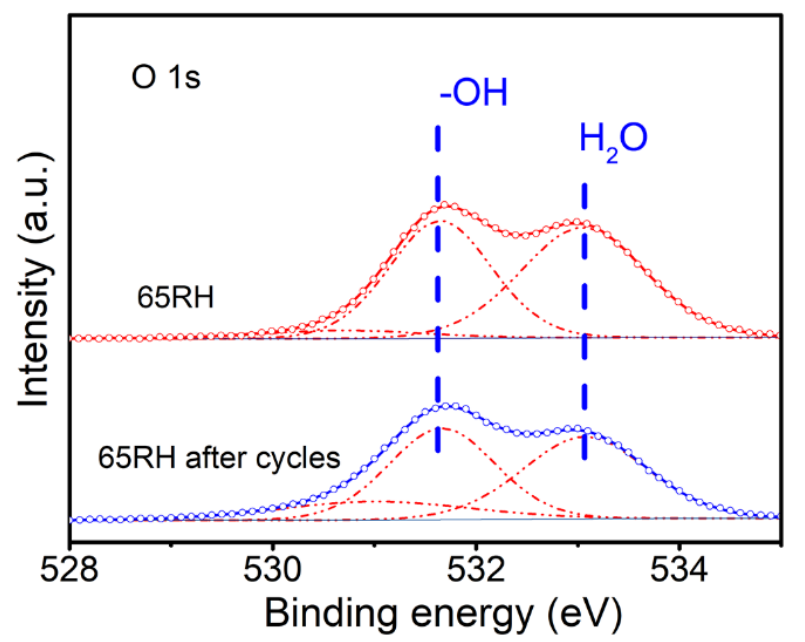

Fig. 2. O1s core level XPS spectra of the 65 RH sample before and after 200 cycles at current density of $1 \mathrm{~A} \mathrm{~g} \mathrm{~g}^{-1}$, demonstrating conclusively that the structural hydroxyl groups are stable during cycling.
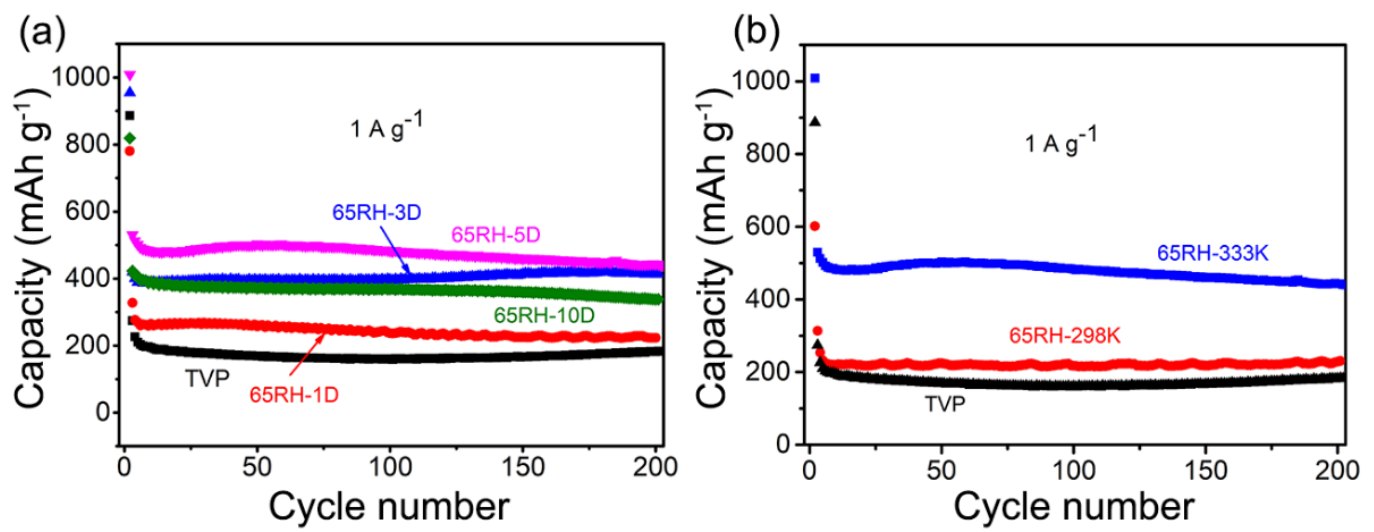

Fig.3. Cycling performances of 'dry' TVP glass treated at 65\% humidity (a) for different time at $333 \mathrm{~K}$ and (b) at different temperature for 5D upon a current density of $1 \mathrm{~A} \mathrm{~g}^{-1}$, confirming the optimum condition for treating the 'dry' TVP glass is $65 \%$ humidity at $333 \mathrm{~K}$ for 5 days. 